\title{
Detection of Ascitic Feline Coronavirus RNA from Cats with Clinically Suspected Feline Infectious Peritonitis
}

\author{
Takehisa SOMA ${ }^{1) * \#}$, Makoto WADA ${ }^{2,3) \#}$, Satoshi TAHARAGUCHI ${ }^{4}$ and Tomoko TAJIMA ${ }^{2)}$ \\ 1) Veterinary Diagnostic Laboratory, Marupi Lifetech Co., Ltd., 103 Fushiocho, Ikeda, Osaka 563-0011, Japan \\ ${ }^{2)}$ Department of Veterinary Science, Graduate School of Life and Environmental Sciences, Osaka Prefecture University, 1-58 Rinku-Orai- \\ Kita, Izumisano, Osaka 598-8531, Japan \\ 3) Tani Animal Hospital, 240-8 Hirai, Naka-ku, Sakai, Osaka 599-8251, Japan \\ 4)Laboratory of Veterinary Microbiology II, Department of Veterinary Medicine, Azabu University, 1-17-71 Fuchinobe, Chuo-ku, \\ Sagamihara, Kanagawa 252-5201, Japan
}

(Received 21 February 2013/Accepted 15 May 2013/Published online in J-STAGE 29 May 2013)

\begin{abstract}
Ascitic feline coronavirus (FCoV) RNA was examined in 854 cats with suspected feline infectious peritonitis (FIP) by RT-PCR. The positivity was significantly higher in purebreds $(62.2 \%)$ than in crossbreds $(34.8 \%)(P<0.0001)$. Among purebreds, the positivities in the Norwegian forest cat $(92.3 \%)$ and Scottish fold $(77.6 \%)$ were significantly higher than the average of purebreds $(P=0.0274$ and 0.0251 , respectively). The positivity was significantly higher in males $(51.5 \%)$ than in females $(35.7 \%)(P<0.0001)$, whereas no gender difference has generally been noted in FCoV antibody prevalence, indicating that FIP more frequently develops in males among FCoV-infected cats. Genotyping was performed for 377 gene-positive specimens. Type I (83.3\%) was far more predominantly detected than type II (10.6\%) $(P<0.0001)$, similar to previous serological and genetic surveys. KEY WORDS: domestic cat, effusive FIP, feline coronavirus, Japan, RNA.
\end{abstract}

doi: 10.1292/jvms.13-0094; J. Vet. Med. Sci. 75(10): 1389-1392, 2013

Feline infectious peritonitis (FIP) is an immune-mediated progressive infectious disease of domestic cats and wild felids caused by infection with feline coronavirus (FCoV), a single-stranded RNA virus classified as Alphacoronavirus $[1,28]$. It is divided into effusive FIP, in which exudate is observed in the body cavity, and non-effusive FIP, in which multiple pyogranuloma lesions are formed, but differences in lesions are influenced by the immunity of individuals [3]. This disease is considered to be induced by a mutant of feline enteric coronavirus (FECV), FIP virus (FIPV) [8, 26]. The incidence is generally about $1 \%$ in FCoV-infected cats, but it varies depending on the age, breed, environment and superinfection with other viruses [7, 8, 17, 23]. There are 2 genotypes of $\mathrm{FCoV}$, and $\mathrm{FCoV}$ type II is considered to arise by recombination between $\mathrm{FCoV}$ type I and canine coronavirus (CCoV) $[9,27]$. Based on serological and genetic investigations, FCoV type I is overwhelmingly dominant over FCoV type II, and mixed infection with both types is not rare $[6,11,14,15]$. Since FIPV and FECV cannot be distinguished serologically or genetically, it is generally difficult to diagnose FIP [1], but it has been stated that the demonstration of FCoV RNA in ascites is one of most reliable diagnostic indicators of FIP [3, 10]. Several results

\footnotetext{
*Correspondence to: Soma, T., Veterinary Diagnostic Laboratory, Marupi Lifetech Co., Ltd., 103 Fushiocho, Ikeda, Osaka 563-0011, Japan.

e-mail: takehisa-soma@ds-pharma.co.jp

\#Contributed equally to the work and therefore should be considered equivalent authors.

(C)2013 The Japanese Society of Veterinary Science
}

concerning the state of FIP incidence have been reported overseas $[6,15,16,18,29]$. In Japan, there have been several reports on the prevalence of FCoV infection [11, 13, 20, 24], but, to our knowledge, no studies on FIP prevalence have been reported. Thus, in this study, to investigate the state of FIP incidence in Japan, we examined FCoV RNA in ascites of domestic cats suspected of having FIP using RT-PCR and investigated the genotype of detected FCoV RNA.

Ascites was obtained from a total of 854 privately owned domestic cats that were clinically suspected of having FIP from veterinary clinics throughout Japan in the period of June 2008 to October 2012. Viral RNA was extracted using a QIAamp Viral RNA Mini Kit (Qiagen, Tokyo, Japan). Detection of FCoV RNA was performed using a QIAGEN OneStep RT-PCR Kit (Qiagen) with the P205-P211 primer pair providing a $223 \mathrm{bp}$ amplicon of the 3'-untranslated region (UTR) gene of FCoV [10], according to the manufacturer's instructions. FIPV strain 79-1146 (American Type Culture Collection, Rockville, MD, U.S.A.) was used as a positive reference virus. Furthermore, for samples in which the 3'UTR gene was detected, genotyping was performed with the nested RT-PCR reported by Addie et al. [4], providing 360 and $218 \mathrm{bp}$ amplicons of FCoV types I and II, respectively. FIPV strain UCD1 (kindly provided by Azabu University) and FIPV strain 79-1146 (same as above) were used as positive reference viruses for the types I and II, respectively. Gene positivity was analyzed by chi-square test (StatView, Adept Scientific, Herts, U.K.), and a $P$ value of $<0.05$ was considered statistically significant.

The 3'-UTR gene was detected in 377 of 854 cats (44.1\%). Grouped by breed, the gene positivity was significantly higher in purebreds $(62.2 \% ; 181$ of 291$)$ than in crossbreds 


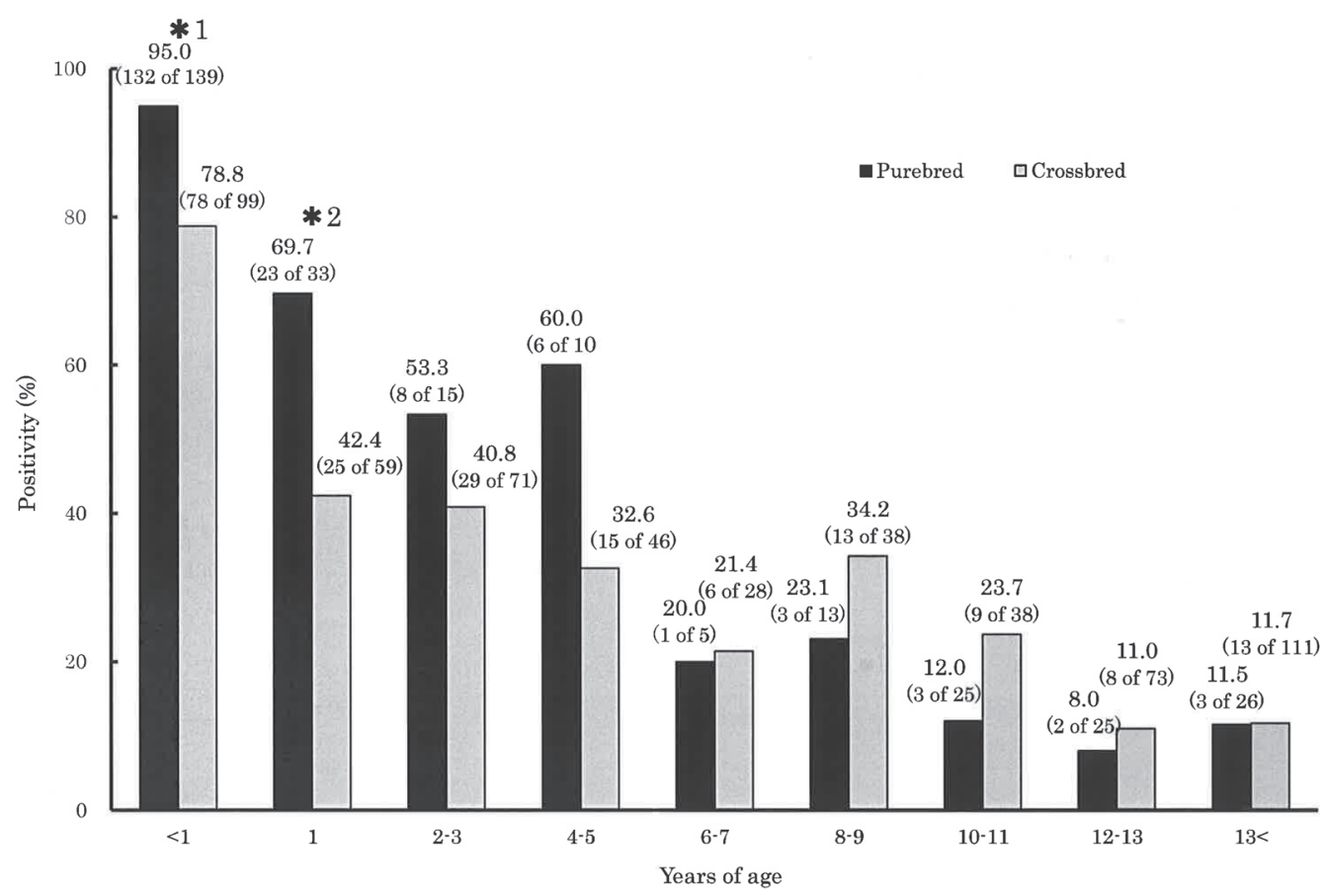

Fig. 1. Age frequency of the ascitic feline coronavirus (FCoV) 3'-untranslated region (UTR) gene from cats with clinically suspected feline infectious peritonitis (FIP). Black and grey bars indicate the positivity of purebreds and crossbreds, respectively. *Significant differences were observed between the purebreds and crossbreds (chi-square test). *1 Less than a year of age; $P=0.0001, \chi^{2}=14.6$. *2 A year of age; $P=0.0119, \chi^{2}=6.3$.

Table 1. Detection of the ascitic feline coronavirus (FCoV) 3'-untranslated region (UTR) gene from cats with clinically suspected feline infectious peritonitis (FIP) grouped by breed

\begin{tabular}{llll}
\hline \multicolumn{1}{c}{ Breed } & \multicolumn{1}{c}{ Positivity } & $\begin{array}{c}\text { P value } \\
\text { vs average of purebreds }\end{array}$ \\
\hline \multirow{4}{*}{ Purebred } & Abyssinian & $47.6 \%(10$ of 21$)$ & $>0.05$ \\
& American shorthair & $30.0 \%(24$ of 80$)$ & $<0.0001\left(\chi^{2}=26.3\right)$ \\
& Maine coon & $60.0 \%(9$ of 15$)$ & $>0.05$ \\
& Norwegian forest cat & $92.3 \%(12$ of 13$)$ & $0.0274\left(\chi^{2}=4.9\right)$ \\
& Persian & $76.7 \%(23$ of 30$)$ & $>0.05$ \\
& Russian blue & $69.2 \%(9$ of 13$)$ & $>0.05$ \\
& Scottish fold & $77.6 \%(45$ of 58$)$ & $0.0251\left(\chi^{2}=5.0\right)$ \\
& Others & $80.3 \%(36$ of 45$)$ & \\
\hline Subtotal (avarege) & $62.2 \%(181$ of 291$)$ & \\
\hline & Crossbred & $34.8 \%(196$ of 563$)$ & $<0.0001\left(\chi^{2}=58.4\right)$ \\
\hline
\end{tabular}

The breeds that consisted of fewer than 10 cats were classified together as others. A significance test $\left(\chi^{2}\right.$ test) was performed between each breed and the average of purebreds $(62.2 \%)$.

(34.8\%; 196 of 563) $\left(P<0.0001, \chi^{2}=58.4\right)$. Thus, age-related changes in positivity were investigated in purebreds and crossbreds. As shown in Fig. 1, the highest positivity was noted in cats younger than 1 year of age in both breeds and decreased with aging after 1 year of age. The positivity was higher in the purebreds than in the crossbreds until 5 years of age, and a significant difference was noted between the purebreds and crossbreds at 1 year of age and younger ( $P=0.0001, \chi^{2}=14.6$ and $P=0.0119, \chi^{2}=6.3$, respectively $)$.
Then, the positivity was investigated in various purebreds. As shown in Table 1, the positivities in the Norwegian forest cat $(92.3 \%)$ and Scottish fold (77.6\%) were significantly higher than the average for purebreds $(62.2 \%)(P=0.0274$, $\chi^{2}=4.9$ and $P=0.0251, \chi^{2}=5.0$, respectively), whereas that in the American shorthair (30.0\%) was significantly lower than the average for purebreds $\left(P<0.0001, \chi^{2}=26.3\right)$; the positivity in the American shorthair was also lower than that in crossbreds, although the difference was not significant. The 
Table 2. Genotyping of feline coronavirus (FCoV) gene from cats with clinically suspected feline infectious peritonitis (FIP) positive for the 3'-untranslated region (UTR) gene

\begin{tabular}{|c|c|c|c|c|c|}
\hline \multirow{2}{*}{ Years of age } & \multirow{2}{*}{ Breed } & \multicolumn{4}{|c|}{ Genotype } \\
\hline & & Type I & Type II & Types I and II & Not detected \\
\hline \multirow{2}{*}{ Younger than 1} & Purebred $n=132$ & $99(75.0 \%)^{b)}$ & $31(23.5 \%)^{\mathrm{c})}$ & $8(6.1 \%)$ & 10 \\
\hline & Crossbred $n=78$ & $74(94.9 \%)^{b)}$ & $3(3.8 \%)^{c)}$ & $1(1.3 \%)$ & 2 \\
\hline \multirow{2}{*}{1 to 4} & Purebred $n=32$ & $27(84.4 \%)$ & $1(3.2 \%)$ & 0 & 4 \\
\hline & Crossbred $\mathrm{n}=58$ & $52(89.7 \%)$ & $2(3.5 \%)$ & $1(1.8 \%)$ & 5 \\
\hline \multirow{2}{*}{5 or older } & Purebred $n=17$ & $15(88.2 \%)$ & $1(5.8 \%)$ & $1(5.8 \%)$ & 2 \\
\hline & Crossbred $n=60$ & $47(78.3 \%)$ & $2(3.3 \%)$ & $2(3.3 \%)$ & 13 \\
\hline Total $n=377$ & & $314(83.3 \%)^{a)}$ & $40(10.6 \%)^{a)}$ & $13(3.4 \%)$ & 36 \\
\hline
\end{tabular}

positivity was low in spring-summer and high in fall-winter, although no significant differences were observed $(38.8$, $40.9,47.3$ and $49.5 \%$ in spring, summer, fall and winter, respectively). Grouped by gender, the positivity was significantly higher in males $(51.5 \% ; 235$ of 456$)$ than in females $(35.7 \% ; 142$ of 398$)\left(P<0.0001, \chi^{2}=21.7\right)$. The positivity was investigated in 10 regions of Japan (Hokkaido, Tohoku, Shinetsu, Kanto, Hokuriku, Tokai, Kinki, Chugoku, Shikoku and Kyushu), but no marked regional difference was noted (data not shown).

Furthermore, the genotype was investigated in 377 specimens positive for the 3'-UTR gene. As shown in Table 2, FCoV type I (83.3\%) was more predominantly detected than FCoV type II $(10.6 \%)\left(P<0.0001, \chi^{2}=399.8\right)$, and both types were detected in $3.4 \%$ of specimens. In 36 specimens, no amplicons were observed; therefore, their genotypes could not be identified. There were no significant differences in the positivity of either type between the purebreds and crossbreds older than 1 year of age. But, at younger than 1 year of age, the positivity of FCoV type I was significantly higher in the crossbreds $(94.9 \%)$ than in the purebreds $(75.0 \%)$ $\left(P=0.0003, \chi^{2}=13.3\right)$, whereas that of $\mathrm{FCoV}$ type II was significantly higher in the purebreds $(23.5 \%)$ than in the crossbreds $(3.8 \%)\left(P=0.0002, \chi^{2}=13.9\right)$. Of 40 cats in which FCoV type II was detected, $31(77.5 \%)$ were purebreds younger than 1 year of age.

Since demonstration of FCoV RNA in ascites of FIPsuspected cats using RT-PCR was a useful indicator to diagnose FIP $[3,10]$, the results of this study likely represent the epidemiology of effusive FIP in domestic cats in Japan. However, whether or not cats negative for the 3'-UTR gene were infected with FCoV was unknown. This status needs to be investigated further, such as by antibody test and quantitative RT-PCR.

In previous surveys, the incidence of FIP was higher in purebreds than in crossbreds, and it was particularly high in specific breeds [16-19, 29]. Similarly, in this study, the positivity of the 3'-UTR gene was significantly higher in purebreds than in crossbreds, particularly in the Norwegian forest cat and Scottish fold, whereas the positivity was lower in the American shorthair. However, in previous reports from the U.S.A. and Australia, the incidence of FIP was high in the Abyssinian, Bengal, Birman, Himalayan, Ragdoll and
Rex and the Australian mist, British shorthair, Burmese and Rex, respectively, and low in the Burmese, Exotic shorthair, Manx, Persian, Russian blue and Siamese and the Persian, respectively $[16,18]$. These breeds are inconsistent with our findings. The breeds that had high and low positivity in this study are consistent with FCoV antibody prevalence in Japan [24]. These findings indicate that countries and regions vary in the incidence of FIP by breed, and the prevalence of $\mathrm{FCoV}$ in breeding colonies seems to be closely related to the incidence, rather than bloodlines.

The positivity was highest in cats younger than 1 year of age and markedly decreased with aging. These findings are consistent with the incidence of FIP in previous reports [2, $6,16,17,19,29]$. At younger than 1 year of age, the positivity was significantly higher in purebreds than in crossbreds, indicating high prevalence of FCoV in multi-cat households, such as pet shops and breeding catteries [8]. The positivity was also significantly higher in males than in females, as previously reported $[6,16,17,29]$. However, no gender difference has generally been noted in the antibody prevalence in previous studies $[5,12,20,24]$, indicating that FIP more frequently develops in males among FCoV-infected cats, although no serological data were shown in this study. This may be due to the influences of the stress of fighting and infectious diseases, such as feline leukemia virus and feline immunodeficiency virus infections, since these viruses more frequently infect males than females [22]. On investigation by season, the positivity tended to increase in fall-winter. A similar tendency has been reported in the U.S.A. [19], suggesting the seasonality of FIP development. This may be related to weather and the estrus cycle.

FCoV type I was far more predominant than FCoV type II, and this is consistent with previous serological and genetic surveys $[6,11,14,15]$. However, most of the FCoV type II cases $(77.5 \%)$ were detected in purebreds younger than 1 year of age. Most purebred cats were likely to have been closely maintained with dogs in pet shops. Considering the fact that the $\mathrm{CCoV}$ infection rate is very high in dogs maintained in multi-dog households [21, 25], this finding epidemiologically may indicate the possibility that FCoV type II is a recombinant of FCoV type I and $\mathrm{CCoV}[9,27]$, although further detailed analyses are necessary for clarifying this relationship. 
The above findings may help to clarify the state of FIP incidence in pet cats in Japan. But, the results were from cats with effusive FIP and are not necessarily applicable to the non-effusive FIP. Moreover, genotype-associated differences in the pathogenicity could not be investigated, because the severity and course of symptoms of the cats from which the test specimens were collected were unclear. It may be necessary to perform epidemiological surveys based on further detailed information and to investigate specimens from cats with non-effusive FIP.

\section{REFERENCES}

1. Addie, D. D. 2012. Feline coronavirus infections. pp. 92-108. In: Infectious Disease of the Dog and Cat, 4th ed. (Greene, C.E. ed.), Saunders Elsevier, St. Louis.

2. Addie, D. D. and Jarrett, O. 1992. A study of naturally occurring feline coronavirus infections in kittens. Vet. Rec. 130: 133-137. [Medline] [CrossRef]

3. Addie, D., Belák, S., Boucraut-Baralon, C., Egberink, H., Frymus, T., Gruffydd-Jones, T., Hartmann, K., Hosie, M. J., Lloret, A., Lutz, H., Marsilio, F., Pennisi, M. G., Radford, A. D., Thiry, E., Truyen, U. and Horzinek, M. C. 2009. Feline infectious peritonitis. ABCD guidelines on prevention and management. $J$. Feline Med. Surg. 11: 594-604. [Medline] [CrossRef]

4. Addie, D. D., Schaap, I. A. T., Nicolson, L. and Jarrett, O. 2003. Persistence and transmission of natural type I feline coronavirus infection. J. Gen. Virol. 84: 2735-2744. [Medline] [CrossRef]

5. Bell, E. T., Malik, R. and Norris, J. M. 2006. The relationship between the feline coronavirus antibody titre and the age, breed, gender and health status of Australian cats. Aust. Vet. J. 84: 2-7. [Medline] [CrossRef]

6. Benetka, V., Kubber-Heiss, A., Kolodziejek, J., Nowotny, N., Hofmann-Parisot, M. and Mostl, K. 2004. Prevalence of feline coronavirus types I and II in cats with histopathologically verified feline infectious peritonitis. Vet. Microbiol. 99: 31-42. [Medline] [CrossRef]

7. Foley, J. E. and Pedersen, N. C. 1996. The inheritance of susceptibility to feline infectious peritonitis in purebred catteries. Feline Pract. 24: 14-22.

8. Hartmann, K. 2005. Feline infectious peritonitis. Vet. Clin. North Am. Small Anim. Pract. 35: 39-79. [Medline] [CrossRef]

9. Herrewegh, A. A. P. M., Smeenk, I., Horzinek, M. C., Rottier, P. J. and de Groot, R. J. 1998. Feline coronavirus type II strains 79-1683 and 79-1146 originate from a double recombination between feline coronavirus type I and canine coronavirus. J. Virol. 72: 4508-4514. [Medline]

10. Herrewegh, A. A. P. M., de Groot, R. J., Cepica, A., Egberink, H. F., Horzinek, M. C. and Rottier, P. J. M. 1995. Detection of feline coronavirus RNA in feces, tissues, and body fluids of naturally infected cats by reverse transcriptase PCR. J. Clin. Microbiol. 33: 684-689. [Medline]

11. Hohdatsu, T., Okada, S., Ishizuka, Y., Yamada, H. and Koyama, H. 1992. The prevalence of types I and II feline coronavirus infections in cats. J. Vet. Med. Sci. 54: 557-562. [Medline] [CrossRef]

12. Holst, B. S., Englund, L., Palacios, S., Renstrom, L. and Berndtsson, L. T. 2006. Prevalence of antibodites against feline coronavirus and chlamydophila felis in Swedish cats. J. Feline Med. Surg. 8: 207-211. [Medline] [CrossRef]

13. Ishida, T., Washizu, T., Fukuoka, J., Toriyabe, K., Uchino, T. and Motoyoshi, S. 1987. Feline infectious peritonitis virus antibody test using enzyme-linked immunosorbent assay. Jpn. J. Vet. Sci. 49: 145-149. [Medline] [CrossRef]

14. Kummrow, M., Meli, M. L., Haessig, M., Goenczi, E., Poland, A., Pedersen, N. C., Hofmann-Lehmann, R. and Lutz, H. 2005. Feline coronavirus serotypes 1 and 2: Seroprevalence and association with disease in Switzerland. Clin. Diagn. Lab. Immunol. 12: 1209-1215. [Medline]

15. Lin, C. N., Su, B. L., Wang, C. H., Hsieh, M. W., Chueh, T. J. and Chueh, L. L. 2009. Genetic diversity and correlation with feline infectious peritonitis of feline coronavirus type I and II: 5-year study in Taiwan. Vet. Microbiol. 136: 233-239. [Medline] [CrossRef]

16. Norris, J. M., Bosward, K. L., White, J. D., Baral, R. M., Catt, M. J. and Malik, R. 2005. Clinicopathological findings associated with feline infectious peritonitis in Sydney, Australia: 42 cases (1990-2002). Aust. Vet. J. 83: 666-673. [Medline] [CrossRef]

17. Pedersen, N. C. 1976. Feline infectious peritonitis: something old, something new. Feline Pract. 6: 42-51.

18. Pesteanu-Somogyi, L. D., Radzai, C. and Pressler, B. M. 2006. Prevalence of feline infectious peritonitis in specific cat breeds. J. Feline Med. Surg. 8: 1-5. [Medline] [CrossRef]

19. Rohrbach, B. W., Legendre, A. M., Baldwin, C. A., Lein, D. H., Reed, W. M. and Wilson, R. B. 2001. Epidemiology of feline infectious peritonitis among cats examined at veterinary medical teaching hospitals. J. Am. Vet. Med. Assoc. 218: 1111-1115. [Medline] [CrossRef]

20. Soma, T., Yasukawa, A. and Kai, K. 2002. Serologic survey of the feline immunodeficiency-virus antibody, the feline leukemia-virus antigen, and the feline coronavirus antibody in domestic cats. J. Jpn. Vet. Med. Assoc. 55: 89-93 (in Japanese with English summary).

21. Soma, T., Ohinata, T., Aoki, E. and Kurita, K. 2012. Prevalence of canine coronavirus and canine parvovirus type 2 infections in pet shops in Japan. J. Anim. Clin. Med. 21: 126-129 (in Japanese with English summary).

22. Soma, T., Saito, N., Kawaguchi, M., Kawashima, S. and Okazaki, M. 2012. Prevalence of anti-feline immunodeficiency virus antibodies and feline leukemia virus antigens in domestic cats during the past ten years in Japan. J. Enviro. Dis. 21: 21-27 (in Japanese with English summary).

23. Sparkes, A. H., Gruffydd-Jones, T. J., Howard, P. E. and Harbour, D. A. 1992. Coronavirus serology in healthy pedigree cats. Vet. Rec. 131: 35-36. [Medline] [CrossRef]

24. Taharaguchi, S., Soma, T. and Hara, M. 2012. Prevalence of feline coronavirus antibodies in Japanese domestic cats during the past decade. J. Vet. Med. Sci. 74: 1355-1358. [Medline] [CrossRef]

25. Tennant, B. J., Gaskell, R. M., Jones, R. C. and Gaskell, C. J. 1993. Studies on the epizootiology of canine coronavirus. Vet. Rec. 132: 7-11. [Medline] [CrossRef]

26. Vennema, H., Poland, A., Foley, J. and Pedersen, N. C. 1998. Feline infectious peritonitis viruses arise by mutation from endemic feline enteric coronavirus. Virology 243: 308-319.

27. Vennema, H., Poland, A., Hawkins, K. F. and Pedersen, N. C. 1995. A comparison of the genomes of FECVs and FIPVs and what they tell us about the relationships between feline coronaviruses and their evolution. Feline Pract. 23: 40-44.

28. Woo, P. C. Y., Huang, Y., Lau, S. K. P. and Yuen, K. Y. 2010. Coronavirus genomics and bioinformatics analysis. Viruses $\mathbf{2}$ : 1804-1820. [Medline] [CrossRef]

29. Worthing, K. A., Wigney, D. I., Dhand, N. K., Fawcett, A., McDonagh, P., Malik, R. and Norris, J. M. 2012. Risk factors for feline infectious peritonitis in Australian cats. J. Feline Med. Surg. 14: 405-412. [Medline] [CrossRef] 